\title{
Los españoles y Napoleón antes del bicentenario de la Guerra de la Independencia
}

\author{
The Spaniards and Napoleon before the Bicentennial \\ of the Peninsular War
}

\author{
Vicente León Navarro \\ Rafael Fernández Sirvent
}

El presente dossier sobre «Los políticos europeos y Napoleón» permite referirnos a algunos trabajos sobre Napoleón y España o Napoleón y los españoles como parte de ese complejo entramado europeo que fueron el Imperio y las guerras napoleónicas. España pesó mucho en los recuerdos de Santa Helena en un hombre que, en la soledad de su prisión, confesaba amargamente el error de haber menospreciado a un pueblo al que no conocía, al que exigió mucho, dio poco y se sublevó al ser traicionado. Un hombre abatido que, en la plenitud de su poder, pensó regenerar a una España que, en su opinión, pedía a gritos ayuda contra el mal gobierno de Godoy. Así rezaban los variopintos informes con los que fraguó su España imaginaria desde los sucesos de El Escorial, aunque la experiencia y avatares de las complejas relaciones anteriores pesaron en su decisión final. Creyó hacerlo en paz, cambiando una dinastía caduca, inerte, impotente y ridícula, a la que odiaba, y a un favorito al que aborrecía, por otra nueva. Pero no contó con la reacción de los españoles -que no eran Godoy- ni estuvo atento a las necesidades de su hermano José. Pretendió tal vez ser regenerador y salvador, pero actuó como mero usurpador. Su error, tras meses de reflexión y de acopio de informes sobre España, fue prescindir de un despreciable Fernando VII, un juguete en sus manos, sin tener en cuenta que era (o se iba a convertir en) el rey deseado. Hubiera sido un aliado dócil, sumiso y agradecido. La empresa que se presentaba fácil a sus ojos, a los de sus consejeros e informadores, resultó ser la tumba de sus 
aspiraciones, de su gloria y, quizás, de sus nobles ideales para la Europa del momento.

Si la Guerra de la Independencia ha sido objeto de numerosas publicaciones y estudiada desde muchos puntos de vista, la relación de Napoleón con España no ha merecido quizá tanta atención. No significa que haya habido descuido y falten estudios, pues ya en 1818 Alberto Baldrich publicaba Historia de la guerra de España contra Napoleón. Pero fue su muerte la que despertó un enorme interés por aquella figura legendaria y mítica. En España aparecieron numerosas obras, unas en castellano y otras traducidas del francés, aunque la mayor parte de ellas tratasen aspectos muy concretos de su vida, acciones militares, conquistas o legislación. Por otra parte, la invasión napoleónica influyó poderosamente en la organización posterior española que deseaba una nueva administración más eficaz y un Estado más sólido. Pasada pues la guerra, los odios contra Napoleón también cambiaron. Incluso aparecieron folletos en alabanza de un hombre benéfico. En la memoria de muchos afrancesados, la intervención del Emperador en España quedó como la ocasión perdida para un cambio necesario; para los liberales propició el despertar de los españoles de su servidumbre, iniciando su camino liberador, y para los conservadores permitió a los españoles medirse con los franceses y demostrar su arrojo, heroísmo y amor a las tradiciones.

También en Francia, dispuesta al olvido de la época imperial, surgió gran interés por un Napoleón poliédrico, viendo en él lo que cada uno quería, al monstruo, al héroe y hombre excepcional, al criminal, al traidor o al villano. Cada cual alimentó su propia imaginación. Natalie Petiteau señala al respecto: «L’histoire de l’Empire a mauvaise presse alors que Napoléon a envahi la littérature et la mythologie du XIXe siècle pour constituer ensuit un point de référence de la vie politique française, de moins jusque dans l'entre-deux-guerres, et pour demeurer, aujoud'hui encore, un personnage qui fait rêver quelques fanatiques ou qui inspire quelques romanciers, à l'heure où son tombeau es toujours l'un des moments les plus visité en France»${ }^{1}$. Napoleón, una figura tan alabada como vituperada, tan glorificada como satanizada, fue poco a poco objeto de atención respecto a España a pesar de todas las prevenciones. Jean-René Aymes apunta que la intervención de Napoleón en España ha sido durante mucho tiempo descuidada porque la Guerra de la Independencia fue poco gloriosa para los franceses ${ }^{2}$.

1. Petiteau, Natalie, Napoléon, de la mythologie à l'histoire, Paris, Éditions du Seuil, 2004 p. 7.

2. AYMES, Jean-René, L'Espagne contre Napoléon. La guerre d'Indépendance espagnole (18081814), Paris, Nouveau Monde Éditions, Fondation Napoléon, 2003. 
Algunos autores pues se embarcaron en la tarea de afrontar esta interesante época. Uno fue Geoffroy de Grandmaison, que publicó en 1908 L’Espagne et Napoleón. Obra que contaba con una buena documentación, pero adolecía de un análisis histórico riguroso, al tiempo que su autor dejaba entrever en exceso tanto su nacionalismo como su carácter conservador. Otro, Jean Lucas-Dubreton, publicaba en 1946 Napoléon devant l'Espagne: ce qu'a vu Goya, con criterios y puntos de vista acertados. Un tercero, aunque a escala regional, fue Pierre Conard que defendía su tesis en 1910 sobre Napoléon et Catalogne. Finalmente, André Fugier, daba a la luz en 1930 Napoléon et Espagne, obra recientemente publicada en España con el título Napoleón y España. 1799/18083. La obra fue importante y pionera en su época, escasa en publicaciones de este tipo, y sigue siéndolo en la actualidad. En la presentación de la edición de 2008, el profesor Emilio La Parra destaca el carácter crítico y riguroso de su autor, lo cual permitió que la obra se convirtiera en consulta obligada para muchos historiadores posteriores. Fugier se documentó muy bien e hizo planteamientos acertados sobre la situación española y las intenciones de Napoleón, aunque no le faltaron apreciaciones personales más propias de la pasión que del rigor histórico, cayendo en algunos errores que criticaba en otros.

Como señala Emilio La Parra, el trabajo de Fugier no ha sido superado y aún hoy resulta imprescindible para conocer la compleja situación política de la España de finales del XVIII y principios del XIX, y en especial para comprender las relaciones diplomáticas entre la España de Carlos IV y la Francia napoleónica ${ }^{4}$. Cierto que en estos momentos no tenemos una obra de esta envergadura, pero los estudios más recientes, tanto en Francia como en España, han actualizado y mejorado en algunos aspectos la obra de Fugier, como se puede ver en numerosos trabajos y, en concreto, en las dos obras que intentaremos presentar de un modo resumido. Una, fruto de un Coloquio Internacional dirigido por el profesor Gérard Dufour y celebrado en Aix-enProvence en 1983, cuyas actas se publicaron en 1984 con el título de Les Espagnols et Napoléon, y la otra, Annales historiques de la Révolution française con un monográfico dedicado a L'Espagne et Napoleón, correspondiente al número

3. Fugier, André, Napoleón y España, 1799-1808, presentación de Emilio La Parra, traducción de Elena Bernardo y Alicia Martorell, Madrid, Centro de Estudios Políticos y Constitucionales-Sociedad Estatal de Conmemoraciones Culturales, 2008, 831 pp.

4. Otra rica fuente de información sobre el tema son las Memorias de Manuel Godoy, obra que cuenta con una completa y reciente edición y estudio introductorio de Emilio La Parra y Elisabel Larriba, Alicante, Publicaciones de la Universidad de Alicante, 2008, $1985 \mathrm{pp}$. 


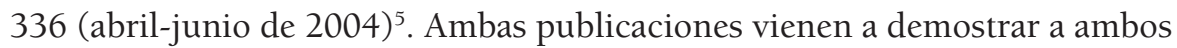
lados de los Pirineos la creciente atención por la figura de Napoleón y su relación con España, interés que se ha visto incrementado en los últimos años con ocasión del bicentenario de la Guerra de la Independencia.

En Les Espagnols et Napoléon intervienen una serie de investigadores que en 1983 presentaban trabajos innovadores, aunque a la altura de 2011 parezca algo lejana aquella fecha. El tema central de las diversas aportaciones es Napoleón-España-los españoles.

Jean Tulard se preguntaba en «Les responsabilités françaises dan la Guerre d'Indépendance» si Napoleón se equivocó respecto de España o lo equivocaron, aunque la decisión de invadirla fue personal. España parecía madura para los cambios, pero equivocó el modo al actuar como invasor. El error, según Louis Trenard en «Images de l'Espagne dans la France napoléonienne», lo originó el desprecio por una España sumisa a Francia desde los Pactos de Familia. Una España al margen de la Europa ilustrada cargada de tópicos negativos. La revolución aumentó los contactos y España ganó interés para los franceses, pero persistieron la mayoría de aquellos estereotipos. Por contra, según Alberto Gil Novales en la «Dualidad napoleónica en España», la imagen de Napoleón antes de 1808 tenía buen cartel entre los españoles, incluso sus tropas gozaron de buena acogida en la Guerra de las Naranjas. La situación cambió con la invasión y la feroz campaña antinapoleónica que se desató por todos los medios imaginables. Campaña en la que pone el acento Jean Battesti Pelegrin en «Nommer l'innommable a propós de la rhétorique des proclamations populaires de la guerre d'Indépendance», para quien la abundancia de textos antinapoleónicos presentados en ocasiones por patriotas anónimos de toda clase muestra la militancia de sus autores. Analiza un buen número de panfletos y habla de los protagonistas, de la visión del enemigo, de cómo se le designa, de la reducción del adversario a través de la retórica del combate. ¿Fue eficaz?, se pregunta. Por su parte, Claudette Dérozier, en «La caricature anti-napoléonienne espagnole», abunda en el tema. La caricatura contra Napoleón la iniciaron los ingleses para combatirle con el desprecio y la calumnia. Lo mismo se hizo en España. La caricatura, como los folletos, recogía la sátira, el ridículo, el odio contra Napoleón. Ahora bien, a diferencia de la europea, la española era más militante, una verdadera imagen de combate para informar, deformar, manipular y satanizar.

5. Este número de Annales historiques de la Révolution française dedicado a LEspagne et Napoléon se puede leer íntegro en la propia Web de la revista: http://ahrf.revues.org/1641 [consulta: 21 de enero de 2011]. 
Levantamientos y propaganda que no debe llevarnos a equívocos respecto al consenso patriótico. Lluís Roura, en «Napoleón: ¿Un punto de acuerdo entre la reacción y el liberalismo en España?», diferencia entre el mito napoleónico positivo que surge tras su muerte y el mito antinapoléonico, político y negativo que se crea desde el inicio de la guerra como oposición al mito fernandino. Pero, paradójicamente, el mito antinapoleónico no es motivo de encuentro entre reaccionarios y liberales, atentos sólo a sus respectivas ideas. Entonces, se pregunta Gérard Dufour, «Pourquoi les espagnols prirent-ils les armes contre Napoléon?». Su visión es novedosa. Los españoles tomaron las armas no para defender a Fernando, sino para defenderse ellos mismos puesto que, contrariamente a su soberano, no aceptaron someterse a los franceses. La religión tampoco tenía nada que ver en los móviles de los españoles en su lucha contra Napoleón. La guerra de España no fue una guerra santa, sino de independencia. Porque movimientos los hubo y muchos, según Antonio Moliner Prada en «Movimientos populares en Cataluña en la Guerra del Francés». Así, se produjeron motines populares en muchos pueblos y la sublevación antinapoleónica tuvo un cariz tanto de guerra popular como antiseñorial, reflejo del malestar existente en el campo. Pero las nuevas instituciones controlaron y canalizaron estas revueltas preservando el orden social vigente.

Napoleón contó con la prensa como arma de propaganda. José Javier Sánchez Aranda, en «Napoleón y la prensa afrancesada en España», destaca el poder de ésta, su coordinación y control entre las distintas publicaciones y el poco influjo que tuvo sobre la población por falta de sintonía con un público ajeno a sus principios. Por otra parte, pocos eran quienes sabían y podían leer. Parece que esta prensa bonapartista fue incapaz de ganarse a la opinión pública. Más eficaz sería la colaboración de los afrancesados que apoyaron a José I. Así lo explica Joan Brines Blasco en «Aproximaciones al estudio sociológico de los franceses en el País Valenciano». Parte de la aristocracia colaboró para encauzar el proceso revolucionario y controlarlo echando mano del ejército napoleónico para aplastar cualquier negativa a pagar los derechos señoriales. La otra parte consideró preferible una revolución controlada que cambiara algo para mantener su preeminencia social. La burguesía vio la ocasión propicia para transformar la sociedad sin traumas. Si el clero fue más remiso en su participación, Anaclet Pons y Justo Serna presentan «El colaboracionismo valenciano en la Guerra del Francés. El canónigo Pascual Fita». Estudian la situación valenciana, la figura del canónigo y su sermón del domingo de Ramos para recordar la entrada de Suchet en Valencia hecha en enero de 1812 y a la que ya había aludido el canónigo Joaquín Más. El sermón se interpretó como afrancesado por sus alabanzas al mariscal y a la monarquía josefina. A 
la vuelta de Fernando se inició un proceso judicial contra ambos canónigos que sufrieron prisión y embargo de sus bienes. El afrancesamiento fue tema debatido y mal resuelto durante mucho tiempo. Genevié Barbé en «Goya et Napoléon» expone cómo Goya evoca a Napoleón y los horrores de la invasión. No le pintó, aunque en algún momento significó la esperanza de la lucha contra el oscurantismo. Las obras de Goya se adaptan a las circunstancias sin renunciar a sus ideas y como filósofo rechaza la barbarie y la crueldad venga de donde venga. Algunos afrancesados lo fueron por convicción, caso de Marchena que estudia Juan Francisco Fuentes en «Marchena y el poder napoleónico (1799-1808)». Colaboró con Napoleón como hombre de orden, en beneficio del sistema burgués, y se alegró cuando en 1808 invadió España, esperando su regeneración y la implantación de un sistema de libertades. No obstante, su indiscreción le acarreó varias veces algunos problemas con la policía, sin llegar a más.

Toda realidad es compleja. Si, como se ha señalado, la imagen de Napoleón mejoró en España tras su muerte, también es cierto que se mantuvo el mito antinapoleónico como demuestran Nelly Clemessy en «Persistance de l'esprit anti-napoléonien dans le conte espagnol ( $2^{\grave{e}}$ moitié du XIXe siècle, debut du XXe)» y Emmanuel Larraz en «La Guerre d'Indépendance dans le cinéma franquiste». En un caso, la Guerra de la Independencia ha servido para mostrar viva en la conciencia nacional la idea de una España fuerte e invencible. Los cuentos han mantenido una imagen simple y parcial de Napoleón y de los franceses para engrandecer el valor de España y de los españoles. Algo similar sucede en el otro caso, donde el cine franquista toma la guerra para exaltar la lucha patriota contra los franceses, defender el nuevo Estado y evocar la guerrilla como grandeza de una raza. A partir de 1951 cambian los gustos de los españoles y dejan de producirse películas como Agustina de Aragón, El Verdugo, El Abanderado o Lola la Piconera. Aline Vauchelle-Haquet, en «L'image de Napoleón à travers les ouvrages en langue espanole publiés en France dans les années qui suivirent sa mort», se fija en la aparición de obras en español en Francia sobre la vida de tan importante personaje, con distintos puntos de vista. En 1821 aparecía la primera y en 1827 se presentaba la traducción de Napoleón en España o historia de la guerra de la península como muestra del interés de los españoles por Napoleón. Por estas fechas sitúa Jean-René Aymes la opinión sobre Napoleón de algunos liberales en «Deux historiens libéraux espagnols face à Napoléon: le comte de Toreno et Francisco Martínez de la Rosa». Frente a mitos y antimitos pintan su retrato físico, intelectual y moral y levantan sus voces sobre el sistema militar, el reformismo o sus sueños. El Emperador se sitúa en un primer plano, pero no es un ser 
esencial, ni extraordinario caudillo, ni político fuera de lo común, ni tampoco un especial conductor de hombres y su papel en España es menor, aunque reconocen el valor de sus leyes. No opinaba igual un padre Luengo, como estudia Rafael Olaechea en «Napoleón visto por un jesuita español exiliado en Italia». Echa mano de una rica cantera, la obra del jesuita, en la que critica con pasión la obra y figura de Napoleón como el perturbador de Europa, sujeto despreciable y vil, azote de Dios y nacido para perseguir la religión y abatir los tronos...

Entre los trabajos restantes, Guy Mercadier escribe «Les Mémoires du Général Palafox: Autobiographie ou autohagiographie?». Aparte de quejarse de la trascripción, considera al personaje muy interesante. Las Memorias, escritas antes de la muerte de Fernando VII, comprenden las distintas partes de su vida, buscando restituir su honor mancillado por la envenenada envidia. Palafox se presenta como buen escritor que sabe poner en escena su vida, su persona y los acontecimientos que giran a su alrededor. José Antonio Ferrer Benimeli, buen conocedor de la masonería, expone en «La masonería bonapartista en España» que si hacia 1782 no existía en España al estar prohibida por la Inquisición, en 1824 parece que la francmasonería estaba instalada desde la guerra. Lo curioso es que Napoleón no fue masón, aunque sí toda su familia, y su régimen contribuyó, como ningún otro, al desarrollo e implantación de la masonería. Se difundió como arma de captación de adeptos a la causa imperial de la mano de José I y de los militares. Emilio La Parra López, en «Guerra y caos fiscal en una ciudad no conquistada. Alicante 1808-1813», demuestra que la guerra supuso para Alicante y para España un descalabro económico, pues al tiempo que aumentaron los gastos militares y de alimentación, disminuyeron los impuestos y la producción, practicándose una fiscalidad nueva que afectó al pueblo llano. Éste no distinguió bien entre exigencias de la guerra y los deseos renovadores del régimen liberal trazado por las Cortes de Cádiz, lo que posibilitó el triunfo del absolutismo quedando en entredicho la labor de las Cortes. Enric Olivé Serret en «Pirates i comerciants. Les relacions d'un corsari francés amb comerciants catalans (1807-1814)» expone un tema curioso. El comerciante Pollan asentado en Barcelona firmó un acuerdo con comerciantes catalanes para armar una nave a fin de ejercer la piratería. Durante tres meses consiguieron un botín de 340.000 duros. La guerra cambió las relaciones y Pollan desapareció sin repartir los beneficios y continuó con la piratería. Acabada la guerra fue detenido, y una vez absuelto se instaló en Niza. Para el autor, la burguesía catalana se presta a invertir en negocios especulativos antes que en manufactureros. Para Jacques Penot el cambio de dinastía fue un descalabro colonial. En «Les hispano-américaines 
et Napoléon» señala la importancia de las Indias en la estrategia de Napoleón, que cedía a su hermano, como rey de España, las Indias con todos sus recursos y permitiendo a los representantes americanos participar en Bayona como un cuerpo diferenciado. Previamente, Napoleón había enviado agentes a América y en mayo organiza varias expediciones para llevar la noticia del cambio dinástico. La operación no tuvo éxito. Los ingleses se encargaron de anunciar el levantamiento de los españoles contra Napoleón y su amistad con Inglaterra. Napoleón, ante la obediencia de las Indias a Fernando VII, decidió apoyar las ideas independentistas enviando agentes.

Lluís Roura presenta el monográfico de Annales historiques de la Révolution française (2004), resaltando la importancia de Napoleón para la historiografía española y de España para la historiografía napoleónica. En este volumen veremos algunos autores que también colaboraron en el encuentro que acabamos de referir. Lluís Roura estudia «Napoléon, héritier des rapports entre l’Espagne et la France révolutionnaire (1795-1804)», y Emilio La Parra López «Méfiance entre les alliés. Les rélations Napoléon-Godoy (1801-1807)». Dos trabajos complementarios tanto en la cronología, como en algunos puntos de vista sobre la situación española y las difíciles y turbulentas relaciones entre Napoleón y Godoy, a quienes, sin embargo, la opinión pública española unió estrechamente. Si Napoleón dedicó poco espacio a Godoy, al que despreciaba por sumiso, ingrato, egoísta y dispuesto a todo por mantenerse en el poder y salvar sus riquezas, Godoy admiraba a Napoleón, aunque le aplicara el correctivo de altanero, inconstante en sus ideas, voluble en sus proyectos y ambiguo. Lluís Roura evidencia la situación de España respecto a Francia y ambas miran la amenaza de Gran Bretaña. La sumisión de España a Francia hace pensar a Napoleón en la invasión de Portugal y mantener buenas relaciones, pero con el Tratado de Fontainebleau la situación cambia por culpa de Godoy en el que vio, según Emilio La Parra, la traición en el Manifiesto de 1806. Napoleón y Godoy intentaron engañarse. El fulgurante ascenso de Godoy le convirtió en pieza clave de la monarquía, lo mismo que Napoleón en Francia. La desconfianza de éste hacia Godoy se transformó en cierto favor al «partido fernandino». ¿Pudieron influir los acontecimientos de El Escorial? Parece que este cambio de actitud dio esperanzas a Fernando, más aún cuando Napoleón lanzaba una campaña en Le Moniteur contra el príncipe de la Paz con dos mensajes: uno que mostraba a un Fernando inocente frente a un culpable Godoy; y otro en el que denunciaba a Godoy enriquecido, venal, intrigante y corrupto, responsable de todos los males de la monarquía. Fernando VII tenía el campo libre para el asalto final y Napoleón para aprovechar el caos de la monarquía y presentarse como el salvador de todos. 
Parte de este período, analizado políticamente, encuentra algunas claves en la situación económica que, desde el punto de vista demográfico, estudia Esteban Canales en «1808-1814: démographie et guerre en Espagne». La ausencia de datos fiables antes y después de la guerra impide cuantificar las pérdidas. A la guerra precedió una virulenta crisis demográfica entre 1800 y 1805, que dificulta el conocimiento exacto de la población al comienzo de la contienda. El autor se sirve de los registros parroquiales y señala que la mortalidad tiende a concentrarse en 1809 y 1812 de forma desigual, según zonas. En 1809 incide más la pérdida de cosechas con sus consecuencias. En 1812 aumenta la crisis de subsistencia, año del hambre. Tras el crecimiento demográfico de 1787-1801, en 1800-1805 se pierde medio millón y durante la guerra, 1808-1814, otro medio. Estudios recientes recortan estas cifras.

En un momento de cambios estratégicos, Charles Esdaile, en «Par delà les monts et dans le lointain: l'armée britannique dan la péninsule ibérique (1808-1814)», defiende que Gran Bretaña hizo pocas reformas militares frente a las novedades francesas. Su potente y eficaz marina controlaba los mares y protegía las Islas de cualquier invasión. Su poderosa milicia guardaba el territorio nacional y su ejército, reducido pero profesional, servía a los aliados en el continente. Inglaterra se había convertido en una «nación en armas», como Francia, con una sexta parte de los hombres uniformados, pero con puntos débiles. No obstante, hubo cambios acordes a la táctica militar francesa. Si Wellington era más tradicional, hubo otros más modernos, pero al final predominó un ejército del Antiguo Régimen movido por tácticas del Antiguo Régimen, mandado por un general del Antiguo Régimen. En España con un general de gran talento en quien confiaban sus soldados, que aguantó el reto francés tanto en ataque como en defensa.

Richard Hocquellet, en «Les élites et le peuple face à l'invasion napoléonienne: pratiques sociales traditionnelles et politique moderne (1808-1812)», Antonio Moliner Prada, en «Crise de l'État et nouvelles autorités: les juntes lors de la Guerre de l'Indépendance», y Vittorio Scotti, en «La guérrilla espagnole dans la guerre contre l'armée napoléonienne», plantean varios puntos de vista sobre la invasión francesa y la respuesta española. Ante todo, según R. Hocquellet, se da una doble paradoja, la división del bando patriota en reaccionarios y liberales y la fractura entre élites y pueblo. El levantamiento popular es la reacción del pueblo frente a la pasividad de autoridades, pero ¿fue espontáneo o magnificado por patriotas posteriores? La situación del momento era compleja y las intrigas de unos y otros visibles. Así que a la vista de los sucesos posteriores, más que de espontaneidad se debería hablar de disponibilidad de la población a creer las noticias, a moverse y a reunirse. La 
ineficacia de las autoridades obligó a formar Juntas -nuevas instituciones-al margen del poder constituido. No se puede hablar de una revolución popular, porque el pueblo estuvo ausente de estas Juntas, pero éstas no se entienden sin la acción popular. Las Juntas se convierten en el motor del cambio político y símbolo de la revolución. Por otra parte, para V. Scotti, la invasión motivó el nacimiento de la guerrilla, alabada por patriotas y vituperada por los franceses por estar formada por bandidos, ladrones, malhechores y bandoleros que impedía el despliegue normal del ejército francés, interrumpía los correos o atacaba por sorpresa. Se discute sobre su eficacia y peso en el desenlace de la guerra. Si para Ch. Esdaile fue negativa, V. Scotti la defiende con argumentos y señala que hizo más daño a los franceses que el ejército regular.

La importancia de la prensa en el campo ocupado lo tratan de forma general y concreta Jean-René Aymes, «La Guerre d’Espagne dans la presse impériale (1808-1814)», y Frédéric Dauphin, «La Gazette nationale de Saragosse». Para el primero la prensa entre 1808 y 1814 es prensa de Estado dirigida a desinformar y manipular según circunstancias y conveniencias. Napoleón controló y orientó el número de periódicos, contenidos y fuentes. En el caso de España, las derrotas no son tanto, sus tropas son ejemplares y aclamadas por doquier. La prensa imperial echa mano de los estereotipos de la leyenda negra pintando a los españoles, a la guerrilla y al ejército con los colores más negros. Algo cambió el sentido de la propaganda entre el Dos de Mayo y la batalla de Bailén con la intención de atraerse a la parte ilustrada de la población. La prensa devalúa el levantamiento, desacredita a las Juntas como ilegítimas y a las Cortes como obra de los ingleses, pero no puede ocultar la oposición a la nueva dinastía, aunque sea obra de grupos insurgentes autónomos y desorganizados, hombres de la peor calaña y poco enemigo para el ejército francés. El segundo se centra en la Zaragoza ocupada y en la Gazeta, cuyos redactores defendieron la modernización de España contra los mismos españoles. Nacida como periódico oficial napoleónico, su redactor principal, Ased, la orientó hacia las ideas ilustradas para hacerla creíble. Respondía a un triple plan de propaganda con ataques a la guerrilla, a las poblaciones que la apoyan y con premios a quienes delataban a sus miembros. Premios y castigos como arma en manos de Suchet, que buscaba el orden y la pacificación. La Gazeta recogía los errores y contradicciones de Napoleón y el discurso de los afrancesados, defendiendo la regeneración y pacificación que encarnaba José I. Para su redactor fue afrancesada en una línea ilustrada, buscando su utilidad social y económica bajo la nueva dinastía. Ased unía afrancesamiento e ilustración de tinte aragonesa, propaganda y utilidad, ideas liberales y fino anticlericalismo, esperanza e ilusión de ver a España entre las naciones más cultas. Disentía 
del afrancesamiento político y apostaba por José. Es un ejemplo de prensa provincial interesante.

En una línea cercana a la prensa afrancesada, Xavier Abeberry Magescas, en "Joseph I et les afrancesados», muestra el interés de los afrancesados en emprender un programa de reformas partiendo de la Constitución de Bayona y de José como el monarca adecuado. Reformas que tuvieron su influencia en la España postbélica, como señala Jean-Philippe Luis en «L`influence du modèle napoléonien en Espagne (1814-1845)». Para X. Abeberry empezaron pronto las defecciones en el bando josefino y los que le fueron fieles insinuaron la necesidad de negociar la paz con los insurgentes, proponiendo una paz separada con Inglaterra, el pago de los gastos al ejército napoleónico, la anexión de Portugal y la vuelta al tesoro nacional de los bienes de Godoy. La proclamación de Fernando VII en agosto de 1808 por el Consejo de Castilla declarando nulas las abdicaciones de Bayona era un aviso importante. El entorno de José se movía en dos direcciones distintas. Unos pretendían la independencia política de España respecto de Francia, con la que podría mantener acuerdos ofensivos y defensivos. Otros miraban más a Napoleón para controlar el país con ayuda militar. En esta línea, el embajador Laforest jugó un papel decisivo al defender por encima de José y de los españoles el prestigio de Francia. Para el autor, José I llevó a cabo importantes reformas en Nápoles, y en España también es destacable su actividad legisladora. J.-Ph. Luis analiza el influjo que tuvo la experiencia napoleónica de la Guerra de la Independencia y la etapa posterior en España. Influjo que se completó con obras de economía, jurídicas y de política. El modelo francés de Estado se veía como algo imitable, sin importar si era napoleónico o bonapartista. Napoleón sólo fue odiado a partir de 1808 y años más tarde se diluía este odio dando paso a la leyenda surgida tras su muerte, unida a las nuevas corrientes liberales sobre la libertad de los pueblos. Cierto que la experiencia del Trienio Liberal vino a recordar la imagen liberticida de los franceses. Si las ideas de Napoleón sobre Europa germinaron en algunos lugares, en España hubo que esperar al nacimiento del Estado liberal moderado, aunque el terreno estaba abonado por el bagaje de algunos políticos afrancesados en la política fernandina con los recuerdos de Bayona, los decretos de Chamartín y las leyes de José I. A partir de 1834 empiezan las reformas, algunas ya esbozadas antes, a pesar de la guerra carlista y del enfrentamiento entre liberales moderados y progresistas, y desde 1840 se adopta el modelo francés en la línea del liberalismo moderado de prescindir del pueblo, que debe contentarse con ser gobernado bien y con justicia. El interés administrativo y político por el modelo napoleónico lo ve Alberto Gil Novales, en «Napoléon, anti-Napoléon en Espagne à partir 
de 1815», en la abundancia de libros publicados en España sobre Napoleón en atención al interés que despertó su figura con ocasión de la Guerra de la Independencia. Muchas obras francesas fueron traducidas al español. Algunas sólo trataron aspectos concretos, otras fueron más generales como la Historia de la Guerra de España contra Napoleón de Alberto Baldrich, aparecida en 1818. Gil Novales incorpora una amplia relación de estas obras.

Finalmente, Irene Castells Oliván ve en «Le libéralisme insurrectionnel espagnol (1814-1830)» un modelo de lucha contra el absolutismo a través del pronunciamiento para reinstaurar la Constitución de Cádiz. El ejército asumía la voluntad nacional y las aspiraciones liberales nacidas de la aventura napoleónica. Pronunciamiento, liberal, guerrillero, junta, etcétera, son palabras españolas que se han hecho universales, como señalaba V. Scotti. La Guerra de la Independencia fue obra del ejército regular y de la guerrilla. El pronunciamiento, precedido de la conspiración, es un fenómeno urbano, liberal y militar que tiene un efecto circular de contagio como medio de presión para cambiar el gobierno sin lucha. El ejemplo fue el pronunciamiento de Riego en 1820, cuyo impacto se verá reproducido en otros países, pero ese liberalismo exaltado del Trienio no tuvo buena prensa y le correspondió a Francia asestarle el golpe definitivo, provocando un nuevo exilio liberal que siguió conspirando y pronunciándose. 